\title{
Synthesis, Characterization and Antifungal Evaluation of Novel Thiochromanone Derivatives Containing Indole Skeleton
}

\author{
Xiao-Yan Han, ${ }^{a}$ Yi-Fan Zhong, ${ }^{a}$ Sheng-Bin Li, ${ }^{a}$ Guo-Chao Liang, ${ }^{a}$ Guan Zhou, ${ }^{a}$ Xiao-Ke Wang,,${ }^{* b}$ \\ Bao-Hua Chen, ${ }^{a}$ and Ya-Li Song*,a \\ ${ }^{a}$ Key Laboratory of Pharmaceutical Quality Control of Hebei Province, College of Pharmaceutical Sciences, Hebei \\ University; Baoding, Hebei 071002, China: and ${ }^{b}$ Key Laboratory of Medicinal Chemistry and Molecular Diagnosis of \\ Ministry of Education, College of Chemistry and Environmental Science, Hebei University; Baoding, Hebei 071002, \\ China.
}

Received May 1, 2016; accepted June 20, 2016; advance publication released online July 2, 2016

Invasive fungal disease constitutes a growing health problem and development of novel antifungal drugs with high potency and selectivity against new fungal molecular targets are urgently needed. In order to develop potent antifungal agents, a novel series of 6 -alkyl-indolo[3,2-c]-2H-thiochroman derivatives were synthesized. Microdilution broth method was used to investigate antifungal activity of these compounds. Most of them showed good antifungal activity in vitro. Compound 40 showed the best antifungal activity, which (inhibition of Candida albicans and Cryptococcus neoformans) can be achieved at the concentration of $4 \mu \mathrm{g} / \mathrm{mL}$. Compounds $4 \mathrm{~b}$ (inhibition of Cryptococcus neoformans), $4 \mathrm{j}$ (inhibition of Cryptococcus neoformans), 4d (inhibition of Candida albicans) and $4 \mathrm{~h}$ (inhibition of Candida albicans) also showed the best antifungal activity at the concentrations of $4 \mu \mathrm{g} / \mathrm{mL}$. The molecular interactions between 40 and the $N$-myristoyltransferase of Candida albicans (PDB ID: 1IYL) were finally investigated through molecular docking. The results indicated that these thiochromanone derivatives containing indole skeleton could serve as promising leads for further optimization as novel antifungal agents.

Key words antifungal activity; antifungal lead compound; thiochromanone; indole; molecular docking

Over the past two decades, the incidence of invasive fungal infections and associated mortality has been increasing dramatically, due to a huge increase in the number of patients undergoing organ transplants, anticancer chemotherapy, or other procedures that cause potential hosts to become immunocompromised. ${ }^{1)}$ However, effective and low toxic antifungal agents are limited. Clinically, Aspergillus fumigatus (mortality rate: 50-90\%), Cryptococcus neoformans (mortality rate: 20-70\%), and Candida albicans (mortality rate: $20-40 \%$ ) have been identied as the most common causes of fungal infections. $^{2-4)}$ For the treatment of these infections, orally active polyenes (e.g., amphotericin B), ${ }^{5)}$ fluorinated pyrimidines (e.g., 5-fluorocytosine), azoles (e.g., fluconazole and voriconazole), ${ }^{6}$ and echinocandins (e.g., caspofungin and micafungin), ${ }^{7)}$ have been widely used in clinic use ${ }^{8}$ (Fig. 1). However, several factors have limited their practical applications. For example, amphotericin B has significant nephrotoxicity and many other side effects. Severe resistance to azoles is increasingly being reported. Echinocandins cannot be orally administrated and are not active against Cryptococcus neoformans. ${ }^{9-11)}$ To sum up, these antifungal agents have achieved limited success in terms of severe resistance, limited efficacy and spectrum, drug related toxicity, non-optimal pharmacokinetics, and other problems. ${ }^{12)}$ Hence, it is urgent to elaborate new, highly potent antibiotics with alternative modes of actions. In this regard, the myristoyl coenzyme A (MCoA)/protein $N$-myristoyltransferase (NMT) is an attractive target. ${ }^{13)}$

NMT is a ubiquitous enzyme present in eukaryotes such as fungi, protozoa and mammals. It catalyzes the transfer of the 14-carbon saturated fatty acid myristate from myristoyl-CoA to the N-terminal glycine residue of a variety of eukaryotic cellular and viral proteins. ${ }^{13)}$ NMT participates in membrane targeting and the function of many proteins in a variety of signal transduction cascades and other critical cellular functions. ${ }^{14)}$ Moreover, NMTs are striking in their remarkable diversity of peptide substrates and diversity in the peptidebinding groove has offered potential of developing speciesspecific inhibitors. ${ }^{14)}$ As a result, NMT has been identified as a potential chemotherapeutic target enzyme for antifungal agents. ${ }^{1)}$

Previously, Sheng and colleagues ${ }^{12)}$ had prepared tetrahydrocarbazole derivatives (Fig. 1) and tested their antimicrobial activity (minimal inhibitory concentration (MIC) range: 0.0156 to $64 \mu \mathrm{g} / \mathrm{mL}$ ). It had broad-spectrum inhibitory activity against a wide range of fungal pathogens. Because the chemical scaffold of this compound differs from that of all reported antifungal agents, it is interesting to investigate its structureactivity relationships (SARs) and discover the novel antifungal lead compound which has a similar skeleton structure to tetrahydrocarbazole derivatives.

Thiochromanone is a versatile reagent that has been extensively utilized in heterocyclic synthesis. ${ }^{15)}$ It had been reported to possess important biological activities. Hoettecke et $a l{ }^{16)}$ had prepared 2-alkenylthiochroman-4-ones and tested their antimicrobial activity. Moreover, in our previous work, ${ }^{17)}$ 1-(4-phenylthiazol-2-yl)-1,4-dihydrothiochroman[4,3c]pyrazole was synthesized and showed good inhibition for Cryptococcus neoformans. Therefore, the biological activity of thiochromanone is well documented and thiochromanone derivatives with antifungal ${ }^{18,19)}$ and antitumor ${ }^{20)}$ activity have been synthesized. These results promoted us to synthesize novel derivatives substituted cyclohexane of tetrahydrocarbazole with thiochroman.

Continuing our efforts on the discovery of thiochroma- 


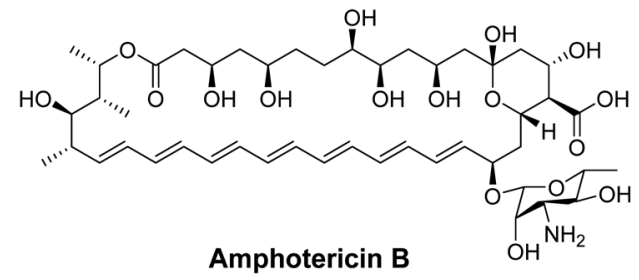
Amphotericin B

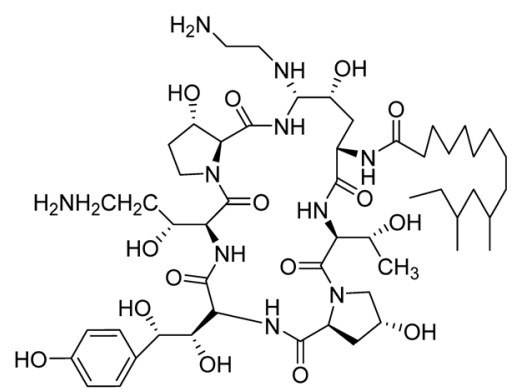

Caspofungin<smiles>Cc1ccc2c(c1)c1c(n2CCCOCc2ccccc2)CCCC1</smiles>

Tetrahydrocarbazole<smiles>OC(Cn1cncn1)(Cn1cncn1)c1ccc(F)cc1F</smiles>

Fluconazole
5-Fluorocytosine<smiles>Nc1nc(=O)[nH]cc1F</smiles>

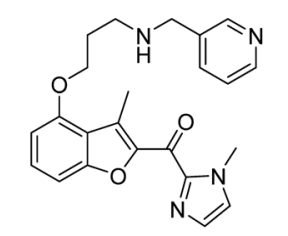

Benzofuran inhibitor 1

Fig. 1. Chemical Structures of Representative Antifungal Agents<smiles>[R]C1CC([R])C2CCSCC2C1O</smiles>

1

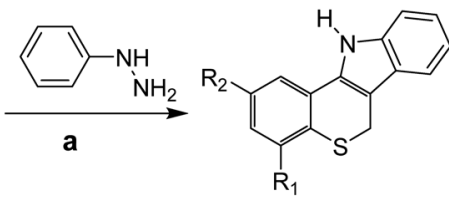

2

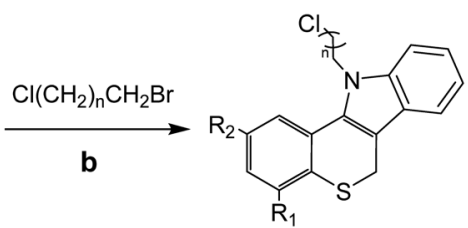

3

c $\downarrow \mathrm{R}_{3}-\mathrm{H}$

$\mathrm{R}_{1}=\mathrm{F}, \mathrm{CH}_{3} ; \quad \mathrm{R}_{2}=\mathrm{CH}_{3}, \mathrm{~F}, \mathrm{Cl}$;
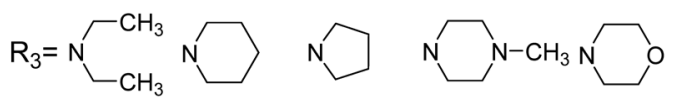

$n=1,2,3$

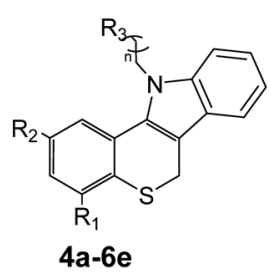

Reagents and conditions: (a) EtOH/reflux/6h/66-75\% (b) $\mathrm{CH}_{3} \mathrm{CN} / \mathrm{NaOH} / \mathrm{reflux} / 6 \mathrm{~min} / 70-78 \%$ (c) $\mathrm{CH}_{3} \mathrm{CN} / \mathrm{K}_{2} \mathrm{CO}_{3} / \mathrm{KI} / \mathrm{reflux}^{2} \mathrm{~h} / 70-91 \%$.

Chart 1. Reagents and Conditions of the Synthetic Compounds $\mathbf{4 a}-\mathbf{6 e}$

none, ${ }^{19)}$ novel 6 -alkyl-indolo[3,2-c]-2H-thiochroman structures were designed and synthesized. We studied their antifungal activities against Cryptococcus neoformans (C. neo.), Candida albicans (C. alb.), Epidermophyton floccosum (E. flo.), Mucor racemosus (M. rac.) and Candida krusei (C. kru.). Crystal structures of $C$. alb. NMT complexed with two classes of inhibitors competitive for peptide substrates have been presented. ${ }^{13)}$ One is a nonpeptidic inhibitor having a benzofuran core (Fig. 1). Molecular docking was performed using the X-ray crystallographic structure of $C$. alb. NMT in complex with the benzofuran inhibitor 1 (Fig. 1) to explore the binding mode of the compound at the active site.

\section{Results and Discussion}

Chemistry By means of Fischer indole synthesis, phenylhydrazine hydrochloride and thiochromanone ${ }^{21,22)}$ in an ethanol solution were heated at reflux for $6 \mathrm{~h}$ to yield compound 2 in $66-75 \%$ yield. Compound 2 was then alkylated in acetonitrile solutions under reflux for $6 \mathrm{~min}$ to obtain compound
3 in $70-78 \%$ yield. Compounds $4-6$ was then obtained by treating 3 with secondary amine $\left(\mathrm{R}_{3} \mathrm{H}\right)$, potassium iodide and anhydrous potassium carbonate in acetonitrile under reflux for about $2 \mathrm{~h}$. After completion of the reaction as indicated by TLC, the reaction mixture was purified by column chromatography (Chart 1).

The structures of all compounds are shown in Table 1. All the compounds were elucidated by high resolution mass spectroscope (HR-MS), ${ }^{1} \mathrm{H}-\mathrm{NMR}$, and ${ }^{13} \mathrm{C}-\mathrm{NMR}$.

Table 2 is shown the reaction conditions exploration of synthetic compound 3. It is clear that the solvent of acetonitrile and reagent of sodium hydroxide are the best reaction conditions of synthetic compound 3 .

Biological Activity In vitro antifungal activity of each compound was expressed as the MIC. As shown in Table 3 , it is clear that target compounds showed weak antifungal activity against E. flo., M. rac. and C. kru., while there is a good antifungal activity against $C$. neo. and $C$. alb. which are invasive fungus. 
Table 1. Structure, Yield, Reaction Time and Melting Point of 6-Alkyl-indolo[3,2-c]-2H-thiochroman 4a-6e

\begin{tabular}{|c|c|c|c|c|c|c|c|}
\hline No. & $\mathrm{R}_{1}$ & $\mathrm{R}_{2}$ & $\mathrm{R}_{3}$ & $n$ & Time (h) & Yield (\%) & $\mathrm{mp}\left({ }^{\circ} \mathrm{C}\right)$ \\
\hline $4 a$ & $\mathrm{H}$ & $\mathrm{F}$ & & 2 & 1.5 & 70 & 102-104 \\
\hline $4 b$ & $\mathrm{H}$ & $\mathrm{F}$ & & 2 & 1.5 & 90 & $70-72$ \\
\hline $4 c$ & $\mathrm{H}$ & $\mathrm{F}$ & $N^{N}$ & 2 & 1.5 & 85 & 104-107 \\
\hline $4 d$ & $\mathrm{H}$ & $\mathrm{F}$ & & 2 & 2 & 85 & $84-86$ \\
\hline $4 e$ & $\mathrm{H}$ & $\mathrm{CH}_{3}$ & & 2 & 2 & 88 & $112-115$ \\
\hline $4 f$ & $\mathrm{H}$ & $\mathrm{CH}_{3}$ & & 2 & 1.5 & 78 & $87-88$ \\
\hline $4 g$ & $\mathrm{H}$ & $\mathrm{CH}_{3}$ & & 2 & 2.5 & 80 & 133-136 \\
\hline $4 h$ & $\mathrm{H}$ & $\mathrm{CH}_{3}$ & & 2 & 1 & 85 & $115-118$ \\
\hline $4 i$ & $\mathrm{CH}_{3}$ & $\mathrm{CH}_{3}$ & & 2 & 1.5 & 70 & $132-134$ \\
\hline $4 j$ & $\mathrm{CH}_{3}$ & $\mathrm{CH}_{3}$ & & 2 & 1.5 & 90 & $110-114$ \\
\hline $4 k$ & $\mathrm{CH}_{3}$ & $\mathrm{CH}_{3}$ & & 2 & 2 & 75 & $120-124$ \\
\hline 41 & $\mathrm{CH}_{3}$ & $\mathrm{CH}_{3}$ & & 2 & 2.5 & 75 & $138-142$ \\
\hline $4 m$ & $\mathrm{CH}_{3}$ & $\mathrm{CH}_{3}$ & & 2 & 2 & 70 & $100-103$ \\
\hline $4 n$ & $\mathrm{H}$ & $\mathrm{CH}_{3}$ & & 2 & 1.5 & 70 & $98-103$ \\
\hline 40 & $\mathrm{H}$ & $\mathrm{Cl}$ & & 2 & 1.5 & 91 & $94-96$ \\
\hline $5 a$ & $\mathrm{H}$ & $\mathrm{CH}_{3}$ & & 3 & 2 & 85 & $134-135$ \\
\hline $5 b$ & $\mathrm{H}$ & $\mathrm{CH}_{3}$ & & 3 & 1.5 & 80 & $122-123$ \\
\hline $5 c$ & $\mathrm{CH}_{3}$ & $\mathrm{CH}_{3}$ & & 3 & 2 & 80 & $122-124$ \\
\hline $5 d$ & $\mathrm{CH}_{3}$ & $\mathrm{CH}_{3}$ & & 3 & 1.5 & 85 & $124-126$ \\
\hline $5 e$ & $\mathrm{H}$ & $\mathrm{F}$ & & 3 & 2 & 87 & $82-84$ \\
\hline $5 f$ & $\mathrm{H}$ & $\mathrm{F}$ & & 3 & 1.5 & 83 & $111-113$ \\
\hline $5 \mathrm{~g}$ & $\mathrm{H}$ & $\mathrm{Cl}$ & & 3 & 2 & 77 & $124-126$ \\
\hline $5 \mathrm{~h}$ & $\mathrm{H}$ & $\mathrm{Cl}$ & & 3 & 1.5 & 81 & $97-99$ \\
\hline $6 a$ & $\mathrm{H}$ & $\mathrm{F}$ & & 1 & 2 & 70 & 102-104 \\
\hline $6 b$ & $\mathrm{H}$ & $\mathrm{Cl}$ & & 1 & 2 & 75 & $98-100$ \\
\hline $6 c$ & $\mathrm{H}$ & $\mathrm{CH}_{3}$ & & 1 & 1.5 & 75 & $100-102$ \\
\hline $6 d$ & $\mathrm{CH}_{3}$ & $\mathrm{CH}_{3}$ & & 1 & 1.5 & 70 & $102-104$ \\
\hline $6 e$ & $\mathrm{H}$ & $\mathrm{F}$ & & 1 & 1.5 & 70 & $99-102$ \\
\hline
\end{tabular}


Table 2. The Influence of Solvent and Reagent on the Yield of Compound $\mathbf{3}^{a)}$

\begin{tabular}{ccc}
\hline \hline Solvent & Reagent & Yield (\%) \\
\hline $\mathrm{C}_{2} \mathrm{H}_{5} \mathrm{OH}$ & $\mathrm{K}_{2} \mathrm{CO}_{3}$ & 3 \\
$\mathrm{C}_{2} \mathrm{H}_{5} \mathrm{OH}$ & $(\mathrm{Et})_{3} \mathrm{~N}$ & - \\
$\mathrm{C}_{2} \mathrm{H}_{5} \mathrm{OH}$ & $\mathrm{NaOH}$ & 11 \\
$\mathrm{CH}_{3} \mathrm{CN}$ & $\mathrm{K}_{2} \mathrm{CO}_{3}$ & 5 \\
$\mathrm{CH}_{3} \mathrm{CN}$ & $(\mathrm{Et})_{3} \mathrm{~N}$ & - \\
$\mathrm{CH}_{3} \mathrm{CN}$ & $\mathrm{NaOH}$ & 76 \\
None & $\mathrm{NaOH}$ & 34 \\
\hline
\end{tabular}

a) All conditions are reflux. "-" represents no reaction.

Table 3. Minimum Inhibitory Concentrations (MIC $\mu \mathrm{g} / \mathrm{mL}$ ) of Target Compounds $^{a}$

\begin{tabular}{|c|c|c|c|c|c|}
\hline \multirow{2}{*}{ Compound } & \multicolumn{5}{|c|}{$\operatorname{MIC}(\mu \mathrm{g} / \mathrm{mL})$} \\
\hline & C. neo. & C. alb. & E. flo. & M. rac. & C. kru. \\
\hline $4 a$ & 128 & 128 & 128 & $>128$ & $>128$ \\
\hline $4 b$ & 4 & 8 & 16 & 64 & 128 \\
\hline $4 c$ & 32 & 16 & 32 & 128 & $>128$ \\
\hline $4 d$ & 8 & 4 & 8 & 64 & 64 \\
\hline $4 e$ & 128 & 128 & 64 & 64 & 64 \\
\hline $4 f$ & 8 & 8 & 16 & 64 & 64 \\
\hline $4 g$ & 64 & 32 & 32 & $>128$ & 128 \\
\hline $4 h$ & 8 & 4 & 8 & 32 & 32 \\
\hline $4 i$ & 64 & 64 & 128 & 128 & 128 \\
\hline $4 j$ & 4 & 8 & 16 & 64 & 64 \\
\hline $4 k$ & 64 & 64 & 64 & $>128$ & 128 \\
\hline 41 & 16 & 16 & 32 & 64 & $>128$ \\
\hline $4 m$ & 32 & 32 & 32 & 64 & 32 \\
\hline $4 n$ & 64 & 32 & 64 & 32 & 64 \\
\hline 40 & 4 & 4 & 16 & 64 & 32 \\
\hline $5 \mathbf{a}$ & 16 & 64 & 32 & 128 & 128 \\
\hline $5 b$ & 64 & 64 & 64 & $>128$ & $>128$ \\
\hline $5 c$ & 8 & 16 & 16 & 64 & 64 \\
\hline $5 d$ & 16 & 8 & 16 & 64 & 64 \\
\hline $5 e$ & 16 & 16 & 16 & 128 & 64 \\
\hline $5 f$ & 16 & 32 & 32 & 64 & 128 \\
\hline $5 g$ & 32 & 64 & 64 & 128 & 64 \\
\hline $5 h$ & 8 & 16 & 16 & 32 & 64 \\
\hline $6 a$ & 32 & 16 & 64 & 64 & 64 \\
\hline $6 b$ & 16 & 16 & 64 & 128 & 64 \\
\hline $6 c$ & 16 & 32 & 64 & 128 & $>128$ \\
\hline $6 d$ & 16 & 16 & 32 & 64 & 64 \\
\hline $6 e$ & 32 & 16 & 16 & 64 & 64 \\
\hline $\mathbf{F}$ & 32 & 32 & 8 & 64 & 16 \\
\hline B & 4 & 4 & 2 & 4 & 2 \\
\hline
\end{tabular}

a) F, Fluconazole. B, Amphotericin B. C. neo., Cryptococcus neoformans. C. alb., Candida albicans. E. flo., Epidermophyton floccosum. M. rac., Mucor racemosus. C. kru., Candida krusei.

We mainly discuss the target compounds antifungal activity against $C$. neo. and $C$. alb., $\mathbf{4 b}, \mathbf{d}, \mathbf{h}, \mathbf{j}$ and $\mathbf{o}$ which have better antifungal activity. Among them, 4o showed the best antifungal activity. Not only is compound 40 antifungal activity against $C$. neo. and $C$. alb. superior to the positive control Fluconazole but also surpassed Amphotericin B activity. Compounds $\mathbf{4 b}$ and $\mathbf{j}$ (inhibition of $C$. neo.) can be achieved at $4 \mu \mathrm{g} / \mathrm{mL}$. Compounds $\mathbf{4 d}$ and $\mathbf{h}$ (inhibition of $C$. alb.) can be achieved at $4 \mu \mathrm{g} / \mathrm{mL}$. In addition, antifungal activity of other

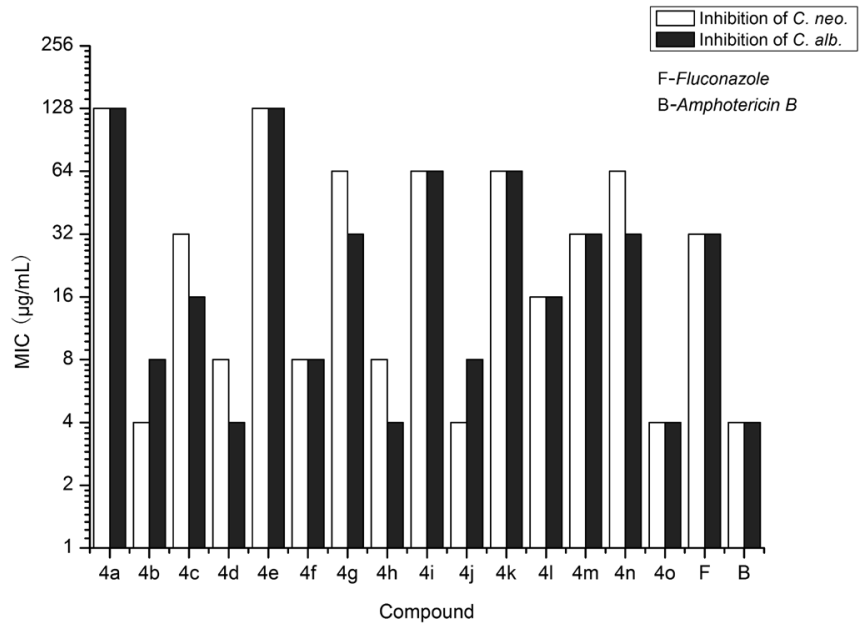

Fig. 2. MIC $(\mu \mathrm{g} / \mathrm{mL})$ of Target Compounds $4 \mathbf{a}-\mathbf{o}$ against $C$. neo. and C. alb.

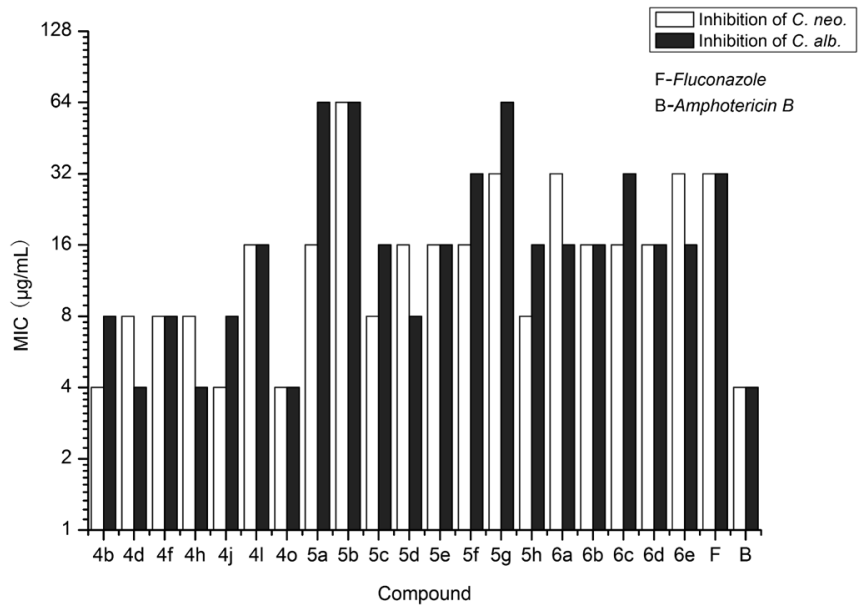

Fig. 3. MIC $(\mu \mathrm{g} / \mathrm{mL})$ of Target Compounds That $\mathrm{R}_{3}$ Is Pyrrolidin or $N$ Methylpiperazine against $C$. neo. and C. alb.

compounds also exceeded the level of fluconazole.

As shown in Fig. 2, the target compounds $\mathbf{4 a - 0}$, when $\mathrm{R}_{3}$ is pyrrolidine, $4 \mathbf{b}, \mathbf{j}$, o $(\mathrm{MIC}=4 \mu \mathrm{g} / \mathrm{mL})$ showed better inhibition activity to $C$. neo. When $\mathrm{R}_{3}$ is $N$-methylpiperazine, the MIC of $\mathbf{4 d}$ and $\mathbf{h}$ is $8 \mu \mathrm{g} / \mathrm{mL}$. When $\mathbf{R}_{3}$ is morpholine, piperidine or diethylamine, the compounds showed weak antifungal activity (MIC $>16 \mu \mathrm{g} / \mathrm{mL}$ ).

Compounds $\mathbf{4 d}$ and $\mathbf{h}$ ( $\mathrm{R}_{3}$ is $N$-methylpiperazine) showed better inhibition activity to $C$. alb. $(\mathrm{MIC}=4 \mu \mathrm{g} / \mathrm{mL})$. When $\mathrm{R}_{3}$ is pyrrolidine, the MIC of $\mathbf{4} \mathbf{b}$, $\mathbf{f}$ and $\mathbf{j}$ is $8 \mu \mathrm{g} / \mathrm{mL}$. When $\mathrm{R}_{3}$ is morpholine, piperidine or diethylamine, the compounds showed weak antifungal activity (MIC $>16 \mu \mathrm{g} / \mathrm{mL}$ ).

Alkane chain of $\mathbf{4 a - 0}$ is three carbon chains, $\mathbf{5 a}-\mathbf{h}$ is four carbon chains and $\mathbf{6 a}-\mathbf{e}$ is two carbon chains. As shown in Fig. 3, while $\mathrm{R}_{3}$ is pyrrolidin or $N$-methylpiperazine, the threecarbon chain alkane compounds $\mathbf{4 a - 0}$ showed the highest antifungal activity.

The inhibition activity to $C$. neo., when $\mathrm{R}_{3}$ is pyrrolidine or $N$-methylpiperazine, $\mathbf{4 b}, \mathbf{d}, \mathbf{h}, \mathbf{j}, \mathbf{o}$ (three carbon chains) $>\mathbf{5 a}-\mathbf{f}$ (four carbon chains) or $\mathbf{6 a}, \mathbf{b}$ (two carbon chains). The inhibition activity to $C$. alb., when $\mathrm{R}_{3}$ is $N$-methylpiperazine or pyrrolidine, $\mathbf{4 b}, \mathbf{d}, \mathbf{f}, \mathbf{h}, \mathbf{j}$ (three carbon chains) $>\mathbf{5 a}-\mathbf{h}$ (four 


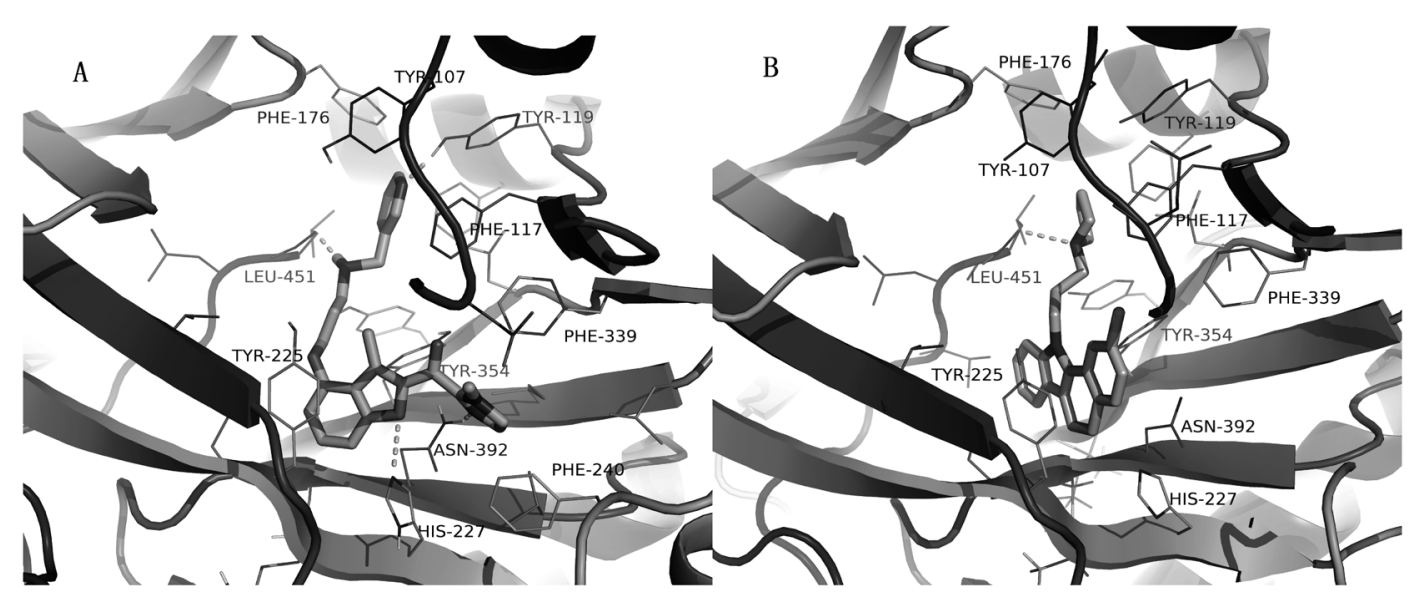

Fig. 4. The Predicted Binding Modes of the Benzofuran Inhibitor 1/4o- $N$-Myristoyltransferase

A: Predicted binding mode of the benzofuran inhibitor 1 docked into the binding site of $N$-myristoyltransferase; B: Predicted binding mode of 40 docked into the binding site of $N$-myristoyltransferase.

carbon chains) or $\mathbf{6 a}-\mathbf{e}$ (two carbon chains).

Molecular Docking In an attempt to correlate the SARs with the binding mode of the synthesized compounds, the benzofuran inhibitor $\mathbf{1}$ which was reported as NMT inhibitor by Ohtsuka and colleagues ${ }^{23)}$ and 40 were docked into the crystal structure of NMT from $C$. alb. (CaNMT). ${ }^{13)}$ The docking results of the benzofuran inhibitor $\mathbf{1}$ and $\mathbf{4 0}$ were shown in Fig. 4.

The overall conformation of the benzofuran inhibitor 1 in the active site of CaNMT was shown in Fig. 4A. The benzofuran ring was located at the center of the active site, surrounded by some hydrophobic residues, such as Tyr225, Tyr354 and Leu394. The phenyl part of the benzofuran ring could form $\pi-\pi$ interaction with Tyr225. The substituted phenyl group of C-2 side chain formed hydrophobic interaction with Phe115 and Phe240. The terminal pyridinyl group C-4 side chain was surrounded by hydrophobic aromatic residues, such as Tyr107, Phe117 and Phe176. Four hydrogen bonds were observed between the benzofuran inhibitor 1 and CaNMT. The second amine group of $\mathrm{C}-4$ side chain made a hydrogen bond with C-terminal carboxylate of Leu451, which is an important functional residue in the catalytic cycle of CaNMT. The oxygen atom of the benzofuran ring and the nitrogen atom of the methylimidazole ring formed two hydrogen bonds with His227 and Asn392, respectively. Another hydrogen bond was formed between the pyridine nitrogen of C-4 side chain and Tyr119 hydroxyl group.

The overall conformation of compound $\mathbf{4 0}$ in the active site of CaNMT was shown in Fig. 4B. The nitrogen atom of the pyrrolidine ring formed one hydrogen bond with Leu451. The indolo[3,2-c]- $2 H$-thiochroman ring was surrounded by some hydrophobic residues, such as Tyr225, Tyr354 and Leu394. The phenyl part of the thiochroman ring could form $\pi-\pi$ interaction with Tyr225. The pyrrolidine ring was surrounded by hydrophobic aromatic residues, such as Tyr107, Phe117 and Phe176. However, three hydrogen bonds were lost for compound 4o, mainly because of the structure of 4o lacking of a chain interacting with the residues His227 and Asn392. The binding mode of compound 40 in the active site of CaNMT was very similar to that of the benzofuran inhibitor. As a result, the similar binding mode contributed to the excellent inhibition activity of compound $\mathbf{4 0}$ against $C$. alb.

\section{Conclusion}

In summary, a novel series of thiochromanone derivatives containing indole skeleton were synthesized and evaluated as antifungal inhibitors. Compound 4o (4-chloro-6-(3-pyrrolidin1-yl-propyl)-indolo[3,2-c]-2H-thiochroman) showed the best antifungal activity in vitro, which (inhibition of $C$. neo. and $C$. alb.) can be achieved at the concentration of $4 \mu \mathrm{g} / \mathrm{mL}$. Moreover, molecular docking was performed to position compound 40 into the $C$. alb. NMT active site to determine the potential binding model. Molecular docking studies rationalized the biological properties of compounds by identifying the possible interactions with the molecular targets. In conclusion, these preliminary results are promising and some of these compounds may be potential candidates for antifungal agents.

\section{Experimental}

General chemistry methods, synthesis procedures, spectral data, biological assays, molecular docking are given in Supplementary materials.

Acknowledgments We gratefully acknowledge the Open Project Program of Key Laboratory of Pharmaceutical Quality Control of Hebei Province, for financial support; the Youth Foundation of Science and Technology Reasearch in Higher Education Institutions of Hebei Province (QN2015039) for financial support; Hebei University innovative funding projects for graduate students. We gratefully acknowledge Dr. Carl LeBlond (Chemistry Department, College of Natural Sciences and Mathematics of IUP) for his helping for grammar and spelling of the paper.

Conflict of Interest The authors declare no conflict of interest.

Supplementary Materials The online version of this article contains supplementary materials.

\section{References}

1) Zhao C., Ma S., ChemMedChem, 9, 2425-2437 (2014).
2) Wiu Y., Wang Y., Dong G., Zhang Y., Wu S., Miao Z., Yao J., Zhang
3) Lai C. C., Tan C. K., Huang Y. T., Shao P. L., Hsueh P. R., J. Infect.


Chemother., 14, 77-85 (2008).

4) Steenbergen J. N., Casadevall A., J. Clin. Microbiol., 38, 1974-1976 (2000).

5) Gallis H. A., Drew R. H., Pickard W. W., Rev. Infect. Dis., 12, 308-329 (1990)

6) Sheehan D. J., Hitchcock C. A., Sibley C. M., Clin. Microbiol. Rev., 12, 40-79 (1999)

7) Denning D. W., J. Antimicrob. Chemother., 49, 889-891 (2002).

8) Wang S., Wang Y., Liu W., Liu N., Zhang Y., Dong G., Liu Y., L Z., He X., Miao Z., Yao J., Li J., Zhang W., Sheng C., ACS Med. Chem. Lett., 5, 506-511 (2014).

9) Sheng C., Zhang W., Curr. Med. Chem., 18, $733-766$ (2011).

10) Casalinuovo I. A., Di F. P., Garaci E., Eur. Rev. Med. Pharmaco., 8, 69-77 (2004)

11) Alex D., Gay-Andrieu F., May J., Thampi L., Dou D., Mooney A., Groutas W., Calderone R., Antimicrob. Agents Chemother., 56, 4630-4639 (2012).

12) Wang W., Dong G., Gu J., Zhang Y., Wang S., Zhu S., Liu Y., Miao Z., Yao J., Zhang W., Sheng C., MedChemComm, 4, 353-362 (2013).

13) Sogabe S., Masubuchi M., Sakata K., Fukami T. A., Morikami K., Shiratori Y., Ebiike H., Kawasaki K., Aoki Y., Shimma N., D’Arcy A., Winkler F. K., Banner D. W., Ohtsuka T., Chem. Biol., 9, 11191128 (2002)

14) Fang W., Robinson D. A., Raimi O. G., Blair D. E., Harrison J. R., Lockhart D. E. A., Torrie L. S., Ruda G. F., Wyatt P. G., Gilbert I. H., van Aalten D. M., ACS Chem. Biol., 10, 1425-1434 (2015).

15) Bondock S., Metwally M. A., J. Sulfur Chem., 29, 623-653 (2008).
16) Hoettecke N., Rotzoll S., Albrecht U., Lalk M., Fischer C., Langer P., Bioorg. Med. Chem., 16, 10319-10325 (2008).

17) Song Y. L., Yang T., Dong Y. F., Wu F., Yang G. L., Chem. Lett., 43, $134-136$ (2014).

18) Wilson K. J., Illig C. R., Subasinghe N., Hoffman J. B., Rudolph M. J., Soll R., Molloy C. J., Bone R., Green D., Randall T., Zhang M., Lewandowski F. A., Zhou Z., Sharp C., Maguire D., Grasberger B., DesJarlais R. L., Spurlino J., Bioorg. Med. Chem. Lett., 11, 915-918 (2001)

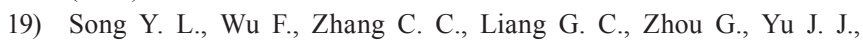
Bioorg. Med. Chem. Lett., 25, 259-261 (2015).

20) Gu X. H., Wan X. Z., Jiang B., Bioorg. Med. Chem. Lett., 9, 569572 (1999).

21) Liu X. M., Yang G. L., Song Y. L., Liu J. J., Wang Y., Zhang D. N., Lett. Org. Chem., 10, 228-234 (2013).

22) Song Y. L., Dong Y. F., Yang T., Zhang C. C., Su L. M., Huang X., Zhang D. N., Yang G. L., Liu Y. X., Bioorg. Med. Chem., 21, 7624-7627 (2013).

23) Kawasaki K. I., Masubuchi M., Morikami K., Sogabe S., Aoyama T., Ebiike H., Niizuma S., Hayase M., Fujii T., Sakata K., Shindoh H., Shiratori Y., Aoki Y., Ohtsuka T., Shimma N., Bioorg. Med. Chem. Lett., 13, 87-91 (2003).

24) National Committee for Clinical Laboratory Standards, "Reference Method for Broth Dilution Antifungal Susceptibility Testing of Yeasts. Approved Standard," 2nd ed., NCCLS Document M27-2A, National Committee for Clinical Laboratory Standards, Wayne, PA, 2002. 